\title{
LXVI. On the electricity of effluent steam
}

\section{W.G. Armstrong Esq.}

To cite this article: W.G. Armstrong Esq. (1840) LXVI. On the electricity of effluent steam, Philosophical Magazine Series 3, 17:112, 452-457, DOI: 10.1080/14786444008650212

To link to this article: http://dx.doi.org/10.1080/14786444008650212

册 Published online: 01 Jun 2009.

Submit your article to this journal 준

Џll Article views: 5

Q View related articles $₫$ 
$452 \mathrm{Mr}$. W. G. Armstrong on the Electricity of Effluent Steam.

original state. From these observations it would appear that with every flash of lightning the cloud became exhausted of its electricity and recharged itself for each succeeding flash.

The air in the cloud seems to move from the periphery to the centre, of the nature of a whirlwind, fluctuating with the leaves of the electroscope, and I had sufficient time to witness twenty-one electric discharges from the cloud in which I was immersed, when the wind became so violent, that the instruments were broken, and I was obliged to cling to the stump of a tree to save myself from being blown over the precipice ; but the uproar around me was increasing and fluctuating with the electric diseharges from the clouds, and the rapid alternations of wet and dry in the clouds, was during the whole time in exact coincidence with the electric discharges.

LXVI. On the Electricity of Effuent Steam. By W. G. Armstrong, Esq.

To the Editors of the Philosophical Magazine and Journal. Gentlemen,

MY letters to Professor Faraday on the remarkable development of electricity which has recently been discovered in a jet of steam issuing from a stean-engine boiler in this neighbourhood, having already appeared in your publication, it is, of course, unnecessary for me here to repeat the circumstances detailed in those letters. I shall therefore take up the narrative of my proceedings, relative to this curious subject, at the point at which the second of those letters concludes.

Having found electricity in all the three boilers I had examined in which water from the neighbouring colliery was used, and not having discorered any indications of it in the boiler which was supplied with rain-water, I was naturally led to believe that the effects I have described were attributable to the peculiar nature of the water from which the electrical steam was produced; and, under this impression, I lost no time in visiting some other high-pressure boilers in the same district, which were also supplied with colliery water, strongly impregnated with lime and other mineral matter. The steam from the safety-valves of these boilers also proved to be electrical, but not to such an extent as I had reason to anticipate from the similarity of the circumstances to those under which electricity was developed in such an extraordinary degree at Seghill. I then proceeded to try a number of boilers in this town and neighbourhood, in which steam was 
propagated under different pressures, and from water of various descriptions; and by insulating myself and holding a conducting-rod in the steam discharged from the safetyvalves, I succeeded in every instance in obtaining electrical sparks, which varied in the different cases from about onefourth to about half an inch in length.

In company with Mr. Robert Nicholson, the engineer of the Newcastle and North Shields railway, I next tried the boilers of the locomotive engines used on that railway, and finding electricity in great abundance in the ejected steam from these boilers, I determined, with Mr. Nicholson's permission and assistance, to institute a set of experiments upon one of them, with a view to a fuller investigation of the subject.

I shall now briefly describe such of these experiments as have been the most inarked in their results, and shall divide them into two classes, first taking those which were chiefly intended to exhibit the extent to which electricity existed in the issuing steam, and then proceeding with the experiments which were undertaken to ascertain the cause of the electric development. Nearly all the experiments were made at night, under cover of the engine-shed, and the atmosphere was generally humid; but when it happened to be otherwise, the quantity of electricity derived from the jet was greatly increased.

Upon trying the steam in the first instance by the method adopted in the previous cases, that is to say, by standing on an insulated stool and holding with one hand a light iron rod immediately above the safety-valve, while the steam was freely escaping, and then advancing the other hand towards any conducting body, sparks of about an inch in length were obtained: but it was som observed, that by elevating the rod in the steam the electricity was gradually increased, and that the maximum effect was not attained until the end of the rod was raised five or six feet above the valve, at which point the length of the sparks occasionally reached two inches. Small sparks were even obtained when the rod was wholly removed from the steam and held in the atmosphere at the distance of two or three feet from the jet, and the electricity thus drawn from the air was positive, like that of the steam. When the rod was extended into the cloud of vapour which accumulated in the upper part of the shed, electricity was drawn down as by a lightning-conductor from a thundercloud. I endeavoured to ascertain whether any precipitation of moisture, analogous to the formation of rain, accompanied 
454 Mr. W. G. Armstrong on the Electricity of Effluent Steam.

the abstraction of electricity from the steam, and a sprinkling of wet was undocib edly felt on the face and hands by the person holding the rod, so long as he remained insulated, but the effect ceased as soon as the insulation was destroyed.

After fully trying the steam with a simple iron rod, as a conductor, recourse was had to other conductors which presented a larger surface to the steam, but the effect was not materially increased until a bunch of pointed wires of differen $t$ lengths was attached to an iron rod and held in the issuing steam, with the points presented downwards. The iron rod terminated in a round knob at the end next the hand, and from this knob sparks of the measured length of four inches were actually drawn, almost as rapidly as they could be counted, while a stream of electricity was at the same time passing off from the rod, at the part which most nearly approached the chimney of the engine. Very perceptible sparks were also obtained when the points were held in a clear atmosphere, at the distance of at least eight feet from the nearest part of the jet.

In all the preceding experiments, the effect appeared to be proportionate to the quantity of steam discharged from the valve, when other things remained the same; and the electricity became quite imperceptible when the escape was very inconsiderable.

By abruptly raising the valve when the engine-slsed was drrk, the edges of the lever and margin of the brass cup which surrounded the valve, were rendered distinctly luminous with rays of positive electricity which were strongest the instant the valve was lifted, and then quickly subsided, becoming very faint after the lapse of a second.

In proceeding to investigate the cause of this extraordinary development of electricity, the first question which 1 proposed for inquiry was, Where does the steam first become electrical, that is to say, is it electrical in the boiler, or if not, does it become so in passing through the orifice, or not till it escapes into the air? In order to determine which of these three suppositions was correct, the apparatus represented in the annexed figure, and of which the following is a description, was employed.

$A$ is a glass tube passing into the steam chamber through the cock $B$, which was screwed into a hole in the top of the boiler, and was furnished with a stuffing-box to prevent escape between the outside of the tube and inner surface of the cock; C is a stop-cock affixed to the upper end of the glass tube, 
and upon which cock is screwed a second glass tube D terminating in another stop-cock E.

The application of this apparatus will be easily understood. If the steam were in the same state of electricity in the boiler as when it issued into the air, it would necessarily communicate positive electricity to the insulated cock $\mathrm{C}$, in passing through the tube. Or, if the steam acquired its electricity by friction, or otherwise, in the channel through which it was discharged, it could only, in the present instance, do so at the expense of the cock $\mathrm{C}$, which, being insulated, would in that case indicate negative electricity. Or, lastly, if the electricity were developed by condensation, expansion, or any other cause which came into operation after the steam escaped into the air, then the cock $C$ would have neither positive nor negative electricity.

Previously to inserting the lower glass tube in the boiler, the steam was allowed to blow off through the large cock $B$, and the jet which issued from it proved, to the surprise of every one present, almost destitute of electricity. This result completely vitiated the inference $I$ had drawn from the circumstance of not finding electricity in the steam from the rain-water boiler before alluded to, in which case, as I have already stated in my second letter to Professor Faraday, the jet was obtained from the gange cock.

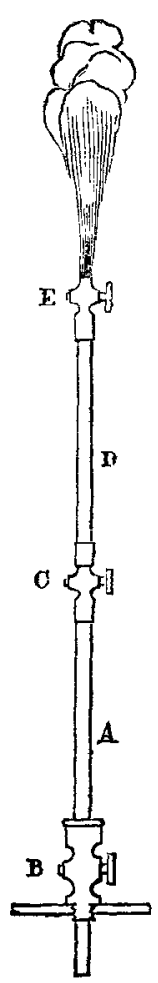

The lower glass tube, without the upper one attached to it, was then passed into the boiler, and a highly electrical jet was obtained from it, which communicated positive electricity to the stop-cock $\mathrm{C}$, from which the steam was discharged. The upper tube was accidentally broken in screwing it on to the lower one, leaving only about three inches of glass above the cock $C$. Under these circumstances the cock $\mathrm{C}$ still continued highly charged with positive electricity, and a pale lambent light flashed at short intervals down the inside of the tube from the cock towards the boiler.

Having replaced the broken glass tube with a new one, the experiment was tried again on a subsequent evening, and the jet being now removed to a much greater distance than before from the cock $C$, no electricity whatever conld be detected in that cock, while the one above it indicated positive 
electricity in a very high degree. It therefore became pretty evident that the electricity was not developed until the steam issued into the atmosphere, and that the upper stop-cock derived its electricity from its contiguity to the jet. One circumstance alone seemed in some degree to militate against this supposition, namely, that the electricity of the cock $E$ was greatly increased when the cock $\mathrm{C}$ was partially closed, as if the expansion which in that case took place in the upper tube rendered the steam electrical previously to its reaching the cock from which the jet was discharged. No negative electricity, however, could be discerned in any part of the apparatus, and without a develoyment of negative electricity, I cannot see how positive electricity can possibly arise from expansion. The more probable explanation of the effect appeared to be, that the partial closing of the middle cock shortened the transparent or non-conducting part of the jet, and thereby caused the electricity to be more readily communicated from the opake part of the jet.

In consequence, no doubt, of increased accumulation of electricity which was thus occasioned in the highest cock, together with the unavoidable dampness of the surrounding medium, the upper glass tube, and the cock above it, became illuminated in the most singular and beautiful manner. Flashes of wavering light flickered round the exterior surface of the glass, and darted from it to the distance of three or four inches, while strong rays of electrical light streamed from the angular parts of the cock, and the flashes from the glass were accompanied by a snapping noise which was distinctly audible amidst the hissing of the steam when the ear was advanced within a short distance from the tube.

The upper glass tube was then removed, and as an additional test of the non-existence of free electricity in the interior of the boiler, a pointed wire was thrust down through the cock $\mathrm{C}$ and tube $\mathrm{A}$ into the steam, and effectual means were used to prevent the escape which would otherwise take place at the cock $\mathrm{C}$, in consequence of the tap remaining open to admit the wire. Now this wire being insulated by the glass tube and communicating with the insulated cock $C$, must have rendered that cock elecirical, if the steam were electrical in the boiler; but not the slightest indication of electricity could, under these circumstances, be found in the cock.

Having withdrawn the pointed wire from the tube, another glass tube, of which the sectional area was about ten times greater than that of the one inserted in the boiler, was then attached to the cock $\mathrm{C}$, in the same manner as the tube I) had been before. The comparatively large bore of this tube 
allowed the steam to expand in a very great degree before it issued into the air, and caused it to be discharged in the state of low-pressure steam; but no diminution of electricity could be perceived in the jet, when thus attenuated; so that the electrical development does not appear to depend upon the degree of violence with which the steam comes in contact with the atmosphere.

The entire absence of negative electricity seemed to preclude the possibility of the phænomena arising from expansion, and the only remaining supposition appeared to be, that the condensation which took place in the jet, set free the electricity which the steam had absorbed in the process of evaporation. This supposition had been previously rendered probable, when it was discovered that the upper and most opake part of the jet yielded the most electricity, although I was at first inclined to attribute that circumstance to the dampness of the steam, in that part of the jet, rendering it a better conductor, and causing it to part more readily with its electricity. Experiments were next, therefore, commenced to ascertain the effect of insulating the boiler, and wholly condensing the steam; but these require repetition before they can be much relied upon. The great difficulty is to effect insulation amidst so much moisture, but $I$ have no doubt that with a little perseverance this object will be accomplished, and I trust I shall be able to furnish, in time for insertion in the next Number of the Philosophical Magazine, such further results as will set the question at rest.

$$
\text { I am, yours, \&c. }
$$

Newcastle upon-Tyne, Nov. 18, 1840. WM. Geo. Armstrong.

LXVII. Further Experiments on the Electricity of Steam. By H. L. Patrinson, Esq., F.G.S.

To the Editors of the Philosophical Magazine and Journal. Gentiemen,

SINCE my last letter to you, dated the 19th ult. (pub$N$ lished at p. 375 of this volume), relative to the electricity of steam issuing from two boilers at Cramlington Colliery, the subject has been further pursued both by myself and others, and sparks have been obtained from the steam of various boilers, in every direction. The mode of operating has generally been that described in my letter, viz. suffering the steam to escape from the safety-valve of the boiler tried, and testing its electricity by holding in it a shovel or an iron rod, the operator standing upon an insulating stool. Sometimes the indications have been very slight, and sometimes there 